\title{
Enhanced Raman scattering and nonlinear conductivity in Ag-doped hollow $\mathrm{ZnO}$ microspheres
}

\author{
Joseph W. Tringe $\cdot$ Harold W. Levie $\cdot$ Scott K. McCall • \\ Nick E. Teslich • Mark A. Wall • Christine A. Orme • \\ Manyalibo J. Matthews
}

Received: 2 July 2012 / Accepted: 4 July 2012 / Published online: 1 August 2012

(c) The Author(s) 2012. This article is published with open access at Springerlink.com

\begin{abstract}
Hollow spherical $\mathrm{ZnO}$ particles doped with $\mathrm{Ag}$ were synthesized with a two-step oxidation and sublimation furnace annealing process. Ag nanoparticle precipitates, as observed by transmission electron microscopy, were present in the polycrystalline $\mathrm{ZnO}$ matrix at $\mathrm{Ag}$ concentrations below $0.02 \mathrm{~mol} \%$, significantly below the $0.8 \mathrm{~mol} \%$ solubility limit for $\mathrm{Ag}$ in $\mathrm{ZnO}$. Enhanced Raman scattering of $\mathrm{ZnO}$ phonon modes is observed, increasing with $\mathrm{Ag}$ nanoparticle concentration. A further enhancement in Raman scattering due to resonance effects was observed for LO phonons excited by $2.33-\mathrm{eV}$ photons as compared with Raman scattering under $1.96-\mathrm{eV}$ excitation. Room-temperature photoluminescence spectra showed both a near-band-edge emission due to free exciton transitions and a mid-gap transition due to the presence of singly ionized oxygen vacancies. $\mathrm{ZnO}: \mathrm{Ag}$ particles were measured electrically in a packed column and in monolithic form, and in both cases displayed nonlinear current-voltage characteristics similar to those previously observed in sintered $\mathrm{ZnO}$ :Ag monoliths where Ag-enhanced disorder at grain boundaries is thought to control current transport. We demonstrate therefore that Ag simultaneously modifies the electrical and optical properties of $\mathrm{ZnO}$ particles through the introduction of vacancies and other defects.
\end{abstract}

\section{Introduction}

Zinc oxide $(\mathrm{ZnO})$ is a semiconductor which has found utility in a broad range of electronic and opto-electronic devices,

J.W. Tringe $(\bowtie) \cdot$ H.W. Levie · S.K. McCall · N.E. Teslich .

M.A. Wall - C.A. Orme · M.J. Matthews

Lawrence Livermore National Laboratory, 7000 East Avenue,

Livermore, CA 94550, USA

e-mail: tringe2@1lnl.gov with recent advances toward practical applications at the nanoscale. For example, $\mathrm{ZnO}$ nanowires have been demonstrated as laser cavities [1, 2], and $\mathrm{ZnO}$ thin films are commonly employed as transparent conducting electrodes in solar cells and light-emitting devices [3-5]. $\mathrm{ZnO}$ is also effective as a fast-switching modulator $[6,7]$. For developing useful nano- and microscale $\mathrm{ZnO}$ devices, it is important to optimize both $\mathrm{ZnO}$ morphology and dopant incorporation. For example, hollow zinc oxide spheres have been synthesized by several groups and are potentially useful because of their lower density and improved optical properties relative to planar $\mathrm{ZnO}$ films [8-10]. A $\mathrm{Zn}$ sublimation-based process has been hypothesized to explain the hollow particle morphology [11] and this process has been observed in situ with transmission electron microscopy for both nanoparticles and microparticles $[12,13]$. Catalysts such as $\mathrm{Ag}, \mathrm{Au}$, $\mathrm{Ni}$, or Co have also been used to produce nanostructured $\mathrm{ZnO}$ with potentially valuable electrical and optical properties [14]. In particular, enhanced Raman scattering in Agdoped $\mathrm{ZnO}$ structures has been observed [14], but the source of the enhancement is not well understood.

Here we show that $\mathrm{Ag}$-doped $\mathrm{ZnO}$ particles can be formed with embedded $\mathrm{Ag}$ nanoparticles when $\mathrm{Ag}$ is present at a sufficient concentration during thermal processing. We observe enhanced Raman scattering signatures in these particles with embedded $\mathrm{Ag}$ nanoparticles, and hypothesize a correlation between the nanoparticles and the enhanced scattering cross section. Room-temperature photoluminescence (PL) is used to identify oxygen vacancies, defects, and changes in near-band-edge (NBE) emission associated with disorder within the hollow $\mathrm{ZnO}$ microstructure. Finally, we demonstrate nonlinear conductivity in $\mathrm{Ag}$-doped $\mathrm{ZnO}$ particles, similar to that observed in sintered monolithic $\mathrm{ZnO}: \mathrm{Ag}$ samples [15]. 


\section{Particle synthesis}

Doping of $\mathrm{Zn}$ particles is accomplished using a solutionbased plating process. $\mathrm{Zn}$ particles, $1-5 \mu \mathrm{m}$ in diameter, reduce silver in solution so that a small amount of silver is deposited onto the surface of each particle. The zinc is then oxidized at low temperature to form an oxide which prevents agglomeration and melting when the temperature is raised for faster oxidation. After the oxidation step, the remaining zinc is distilled away by heating in flowing argon.

In a typical synthesis process, $10 \mathrm{~g}$ of zinc powder is suspended in $150 \mathrm{ml}$ of deionized water by rapid stirring, and $3 \times 10^{-3}$ moles of $\mathrm{AgNO}_{3}$ in $100 \mathrm{ml}$ of water are added drop-wise over a period of at least an hour. The resulting plated zinc is settled, rinsed twice with $100 \mathrm{ml}$ of water, and drained. Two rinses with methanol (10-15 ml each) are used to remove most of the remaining water, and the powder is then dried at $60{ }^{\circ} \mathrm{C}$ in air. This amount of silver represents a baseline doping for experiments reported here (' $1 \times$ ' doping), and corresponds to the amount of silver that would cover all particles with a monolayer of silver, assuming 1- $\mu \mathrm{m}$ particles and $100 \%$ efficient silver deposition. If the monolayer has a similar atomic density compared to the zinc particle, then this corresponds to a doping concentration of $\sim 10^{19} \mathrm{~cm}^{-3}(\sim 0.02 \mathrm{~mol} \%)$, of which some fraction would be electronically activated by subsequent thermal processing. For the lower doping levels (e.g. ' $0.01 \times$ '), the procedure is the same except that the silver concentration in the doping solution is correspondingly reduced.

Next, a $1 \mathrm{~g}$ aliquot of the doped zinc powder is weighed into a porcelain furnace boat and oxidized in a tube furnace in ambient air with a multi-step process: heating from room temperature to $400{ }^{\circ} \mathrm{C}$ in one hour, followed by a four-hour hold at that temperature. The temperature is then raised to the nominal oxidation temperature of $550{ }^{\circ} \mathrm{C}$ over a one-hour period, and held for six hours. The oxide is allowed to cool in the furnace, and then removed and mechanically pulverized. Following the oxidation step, the same furnace is configured for a pure argon atmosphere $(\sim 0.31 / \mathrm{min}$ flow rate) and the same heating profile is used for distillation, except that the upper hold temperature is $700{ }^{\circ} \mathrm{C}$.

\section{Characterization by SEM, TEM, EDS, Raman spectroscopy, and photoluminescence}

Figure 1a shows a scanning electron microscope (SEM) image of a typical $\mathrm{ZnO}$ particle synthesized by this process, where the particle has been sectioned by a focused ion beam (FIB) to illustrate the hollow morphology. $\mathrm{ZnO}$ microparticle diameters ranged from approximately 1 to $5 \mu \mathrm{m}$ with shell thicknesses of $0.2-1 \mu \mathrm{m}$. Additional details of the hollow particle formation process have been reported elsewhere [11-13]. Figure $1 \mathrm{~b}$ shows a typical transmission electron microscope (TEM) image of a heavily doped $\mathrm{ZnO}$ :Ag particle, in which Ag precipitates are visible in darker contrast; some indicated with solid line circles. Ag precipitate diameters range from tens of $\mathrm{nm}$ to about $100 \mathrm{~nm}$. Energy-dispersive spectroscopy (EDS) was performed on the areas indicated by the solid line circle, and in areas such as shown with the dashed-line circle. Typical spectra are shown in Fig. 1c, demonstrating that the lighter-phase material has an elemental composition of $\mathrm{Zn}$ and $\mathrm{O}$, while the darker areas contain Ag. (Cu from the TEM grid is also present in the EDS spectra.) Selected-area diffraction patterns were also obtained from the matrix material (data not shown) and extracted dspacings were consistent with hexagonal $\mathrm{ZnO}$ crystal structure.

Figures 2 and 3 show TEM images of lighter-doped (Fig. 2) and heavier-doped (Fig. 3) $\mathrm{ZnO}$ particles. TEM samples were prepared by focused ion beam sectioning. In Fig. 2, elemental maps indicate the presence of $\mathrm{Zn}$ and $\mathrm{O}$, and the absence of $\mathrm{Ag}$ in discrete volumes. Figure 3 shows similar maps of $\mathrm{Zn}$ and $\mathrm{O}$, and in Fig. 3d, precipitates of $\mathrm{Ag}$ are highlighted.

Samples of $\mathrm{ZnO}$ powder, undoped and doped with $\mathrm{Ag}$, were characterized with a JY Horiba Raman spectroscopy system equipped with either a $\mathrm{HeNe}(633 \mathrm{~nm}, 1.96 \mathrm{eV})$ or a frequency-doubled diode-pumped $\mathrm{Nd}: \mathrm{VO}_{4}(532 \mathrm{~nm}$, $2.33 \mathrm{eV}$ ) continuous-wave laser source. A $20 \times / \mathrm{NA} 0.28 \mathrm{ob}-$ jective was used to focus on an area of interest, and light from the sample was collected in a backscatter geometry before being dispersed onto a liquid nitrogen-cooled CCD (Princeton Instruments PB-1100) by a 600 lines $/ \mathrm{mm}$ grating. Figure 4 shows Raman spectra obtained from undoped and Ag-doped $\mathrm{ZnO}$ particles with our baseline $\mathrm{Ag}$ concentration (' $1 \times$ Ag plating'), together with a concentration which resulted from $100 \times$ less $\mathrm{Ag}$ in the plating solution (' $0.01 \times \mathrm{Ag}$ plating'). Spectra shown are averages of five separate measurements obtained by integrating for $30 \mathrm{~s}$ each. All spectra have been renormalized in counts/s for clarity, using scaling factors shown in the graphs.

Several first- and second-order scattering bands are observed in Fig. 4a and b for undoped $\mathrm{ZnO}$, which have an apparent weak dependence on laser energy, $E_{\mathrm{L}}$. Specifically, we note the distinct peaks at $205,345,381,418,437,545$, and $581 \mathrm{~cm}^{-1}$, with the peak at $437 \mathrm{~cm}^{-1}$ being dominant. With increased Ag doping, a strong enhancement of Raman scattering was observed over 300 to $600 \mathrm{~cm}^{-1}$. In particular, for $E_{\mathrm{L}}=2.33 \mathrm{eV}$, a first-order mode near $545 \mathrm{~cm}^{-1}$ is strongly enhanced by doping, red shifting in frequency relative to the undoped sample by $\sim 10$ and $\sim 20 \mathrm{~cm}^{-1}$ for $0.01 \times$ and $1 \times$ plated samples, respectively. Under $E_{\mathrm{L}}=1.96-\mathrm{eV}$ 


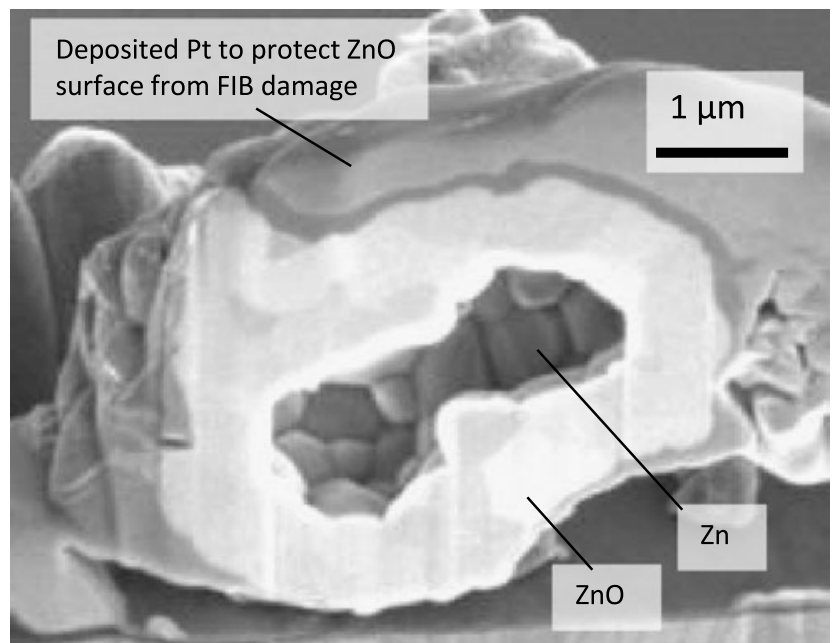

$\mathbf{a}$

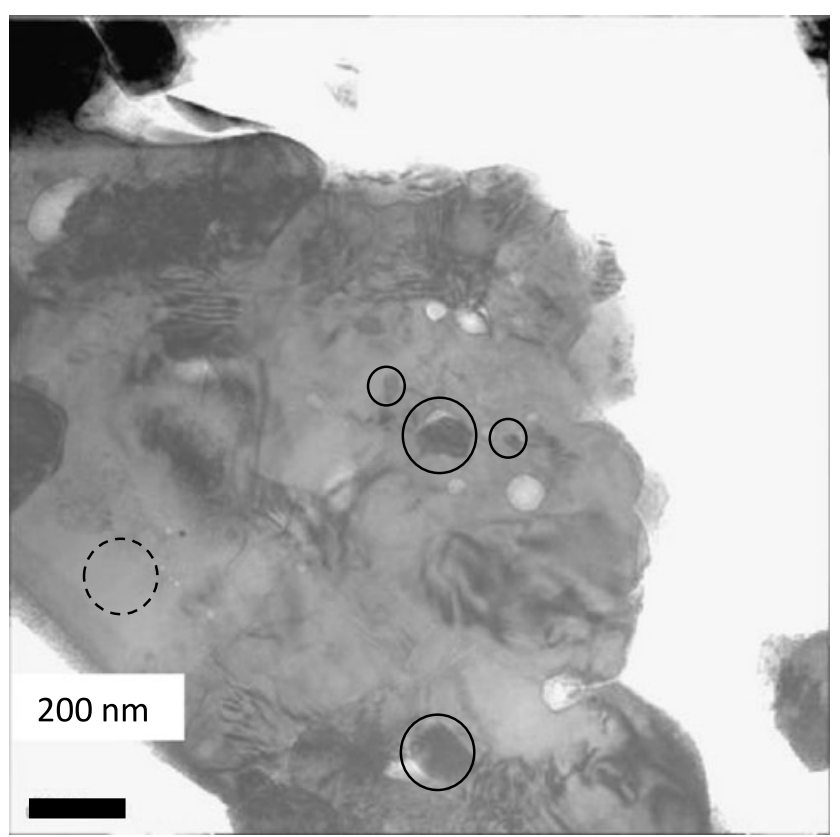

$\mathbf{b}$

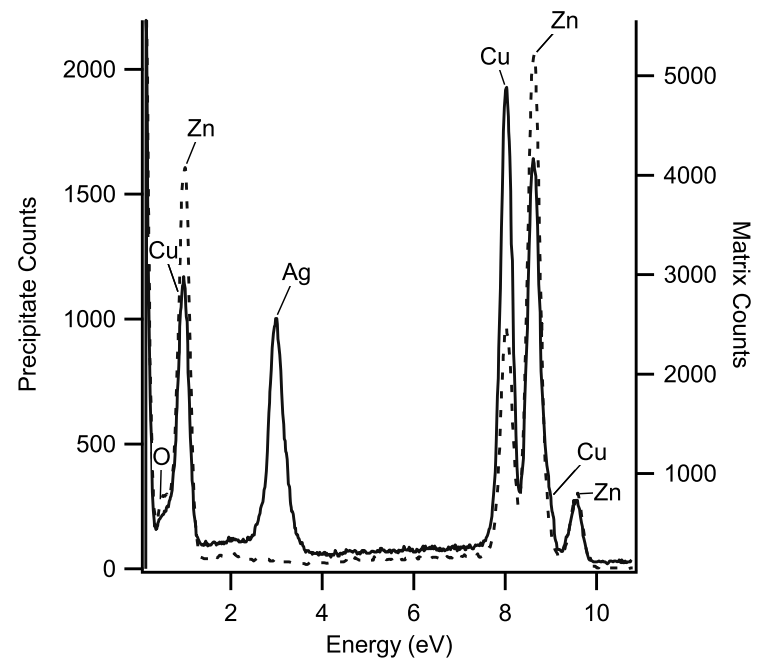

excitation a new mode appears at $\sim 370 \mathrm{~cm}^{-1}$ and also appears strongly enhanced as a function of doping (this feature may also faintly appear in the $1 \times \mathrm{Ag}$ plated spectra for $E_{\mathrm{L}}=2.33 \mathrm{eV}$ ). Aside from the enhanced modes, most features in the undoped $\mathrm{ZnO}$ spectrum diminish substantially at the highest doping levels under both excitations, with the exception of the mode at $437 \mathrm{~cm}^{-1}$, which is faintly visible.

PL measurements were made under ambient conditions ( $T=23{ }^{\circ} \mathrm{C}$ ) using a diode-pumped Nd:YLF laser operating at $351 \mathrm{~nm}$ as the off-axis excitation source and an uncooled Si microspectrometer (Ocean Optics S2042). Figure 5 shows spectra for the undoped and doped $\mathrm{ZnO}$ samples. A strong emission band at $3.25 \mathrm{eV}$ is observed in all samples with a FWHM of $\sim 0.2 \mathrm{eV}$, broadening and slightly blue shifting with Ag nanoparticle doping (inset). For the doped samples, a second broader feature is observed at $2.36 \mathrm{eV}$ with a FWHM of $\sim 0.5 \mathrm{eV}$. Additionally, a strong quench in total PL signal as a function of $\mathrm{Ag}$ incorporation is observed.

\section{Electrical characterization}

For electrical measurements, powder samples were loaded into a capillary tube (radius $1 \mathrm{~mm}$ ) with planar brass electrodes, spring-loaded to provide a constant and repeatable light pressure to the powder during electrical testing. The density of the loaded samples in the capillary was in the range $1.7-2.8 \mathrm{~g} / \mathrm{cm}^{3}(\sim 30-60 \%$ of the density of $\mathrm{ZnO})$. A high-voltage power supply (SRS-PS350) was used to generate an electrical potential across the sample in series with a current meter (HP 3458A multi-meter). The power supply was current limited to $5 \mathrm{~mA}$, while the current meter has picoampere $(\mathrm{pA})$ resolution, but the noise floor limited readings to $\sim 100 \mathrm{pA}$. The applied voltage was typically swept from 20 to $500 \mathrm{~V}$ in $5-\mathrm{V}$ steps over the course of $\sim 20 \mathrm{~s}$, with the applied voltage and current measured at each voltage step. Because of the high voltages involved, the sample holder was wrapped in a thin layer of Teflon and mounted in a probe where the sample holder and leads were electrically well isolated from one another and the probe

4 Fig. 1 (a) SEM image of a $\mathrm{ZnO}$ particle, sectioned by focused ion beam to illustrate hollow morphology. Metallic $\mathrm{Zn}$ residue is visible in this partially distilled cavity, likely formed by the union of two smaller spheroidal particles. Particles which have been electrically and optically characterized for this work are fully distilled so that there is no metallic $\mathrm{Zn}$ remaining (see, for example, (b) and Figs. 2 and 3). (b) Bright-field TEM image of a heavily doped $\mathrm{ZnO}$ particle, in which some dark-contrast precipitates are indicated with solid line circles. EDS spectra from areas corresponding to these circles is shown in (c), indicating that $\mathrm{Ag}$ is present. In a spectrum obtained from the bright-field TEM matrix material (dashed circle in (b)), the elemental content is $\mathrm{Zn}$ and $\mathrm{O}$. $\mathrm{Cu}$ indicated in the spectra is from the TEM grid 

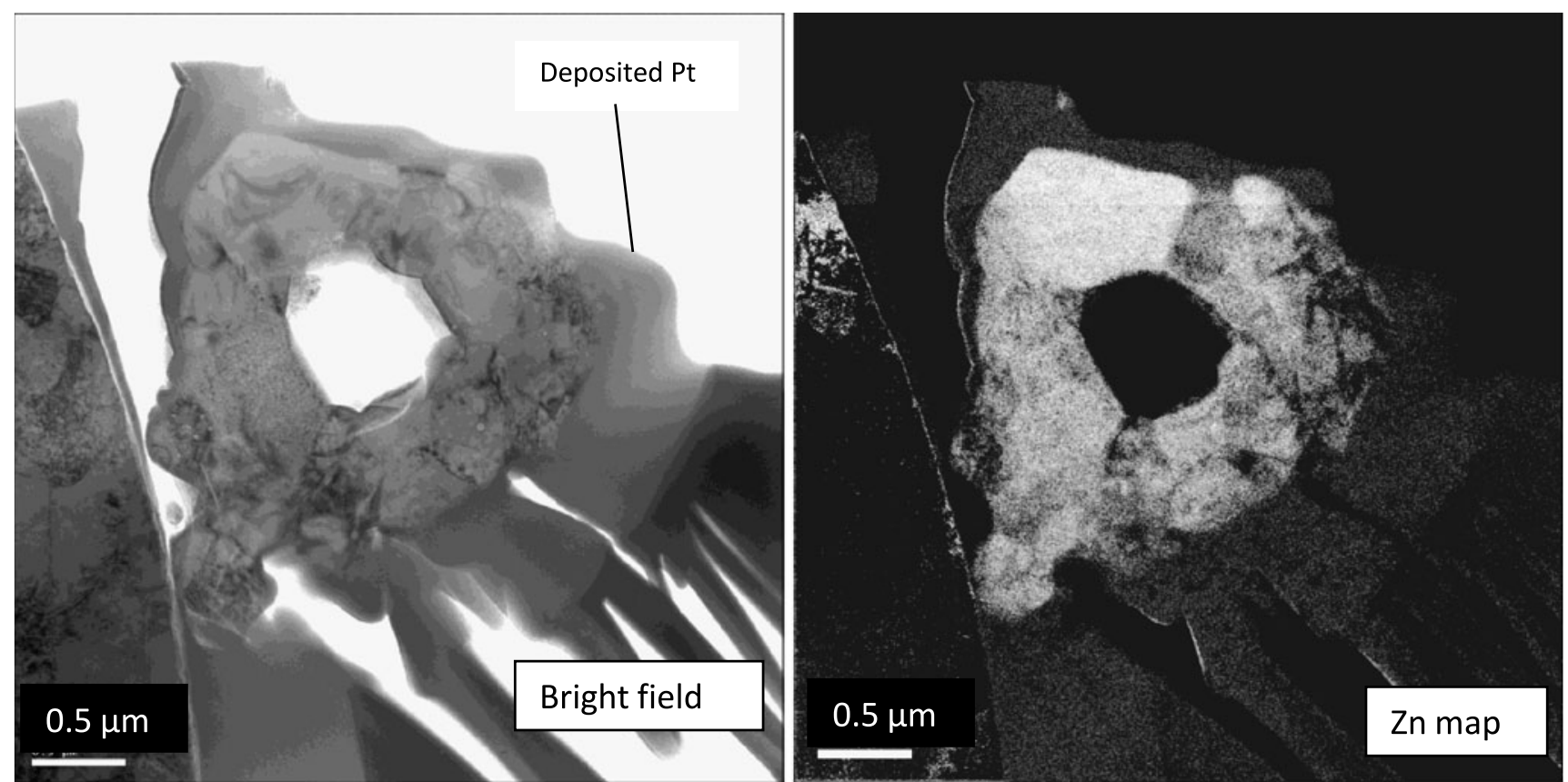

a

b
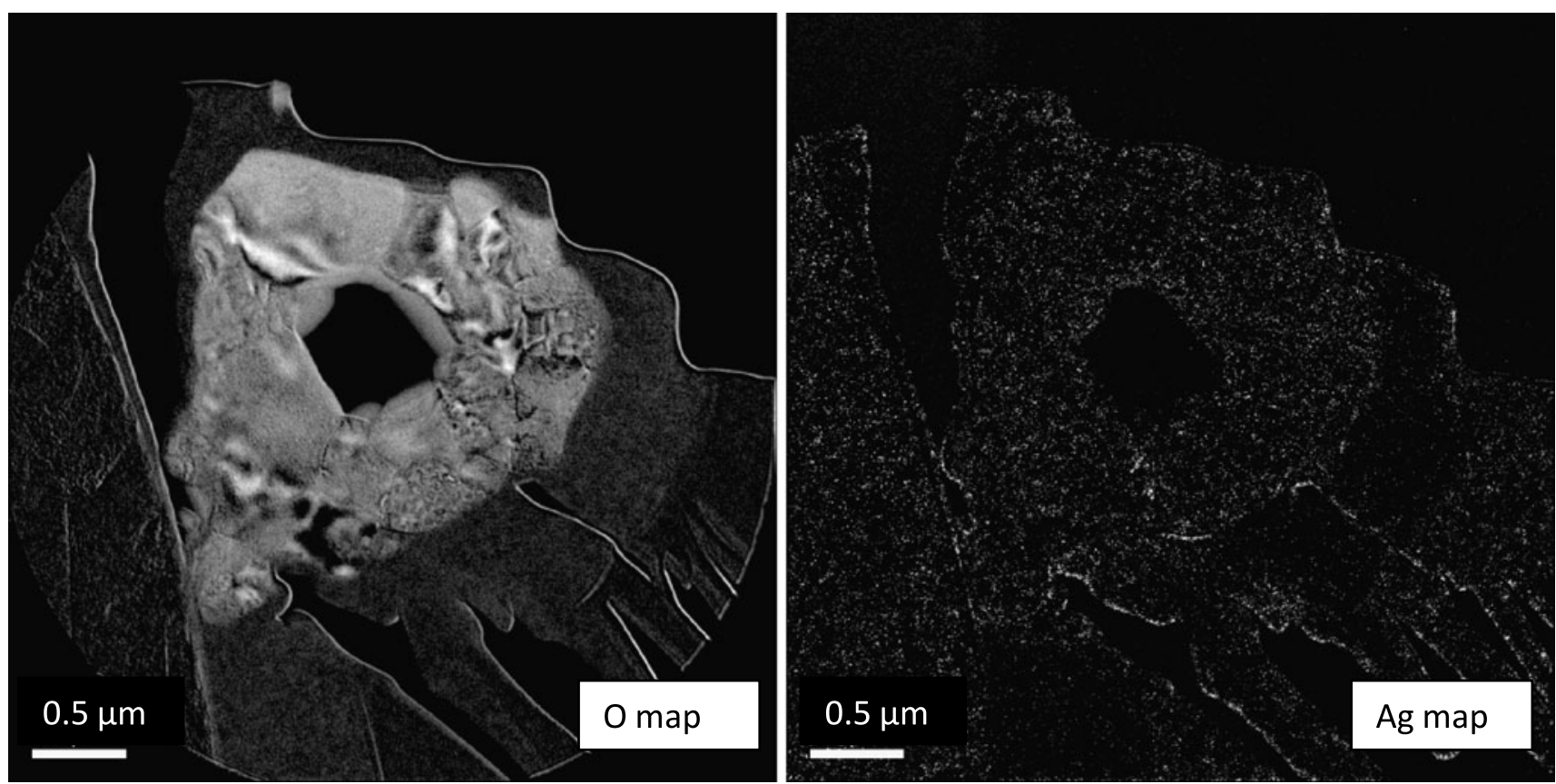

d

Fig. 2 TEM images of $0.01 \times$ plated Ag-doped $\mathrm{ZnO}$ indicating the broadly dispersed, heterogeneous distribution of $\mathrm{Ag}$ within the $\mathrm{ZnO}$ particle. The spatial overlap of $\mathrm{Zn}(\mathbf{b})$ and $\mathrm{O}$ (c) maps indicates that this $\mathrm{Zn}$ particle is fully oxidized. No $\mathrm{Ag}$ particles of significant

but in good thermal contact with the cryostat, which maintained sample temperatures constant at $23{ }^{\circ} \mathrm{C}$ during measurements.

Figure 6 shows representative current density/electric field strength characteristics for a samples of $\sim 4.3 \mathrm{mg} 1 \times$ size are visible in (d). Pt was deposited prior to FIB sectioning of the TEM sample. Note the absence of metallic $\mathrm{Zn}$ in the cavity in this fully distilled particle, contrasting the partially distilled particle shown in Fig. 1a

and $0.01 \times$ doped $\mathrm{ZnO}: \mathrm{Ag}$ particles, as measured in a packed powder column. These samples were $\sim 0.54-\mathrm{mm}$ long, and measurements shown were obtained at $23{ }^{\circ} \mathrm{C}$. Note the power law exponents of 4.3 for the $0.01 \times \mathrm{Ag}$ plated particles, and 3.5 for the $1 \times \mathrm{Ag}$ plated particles. 

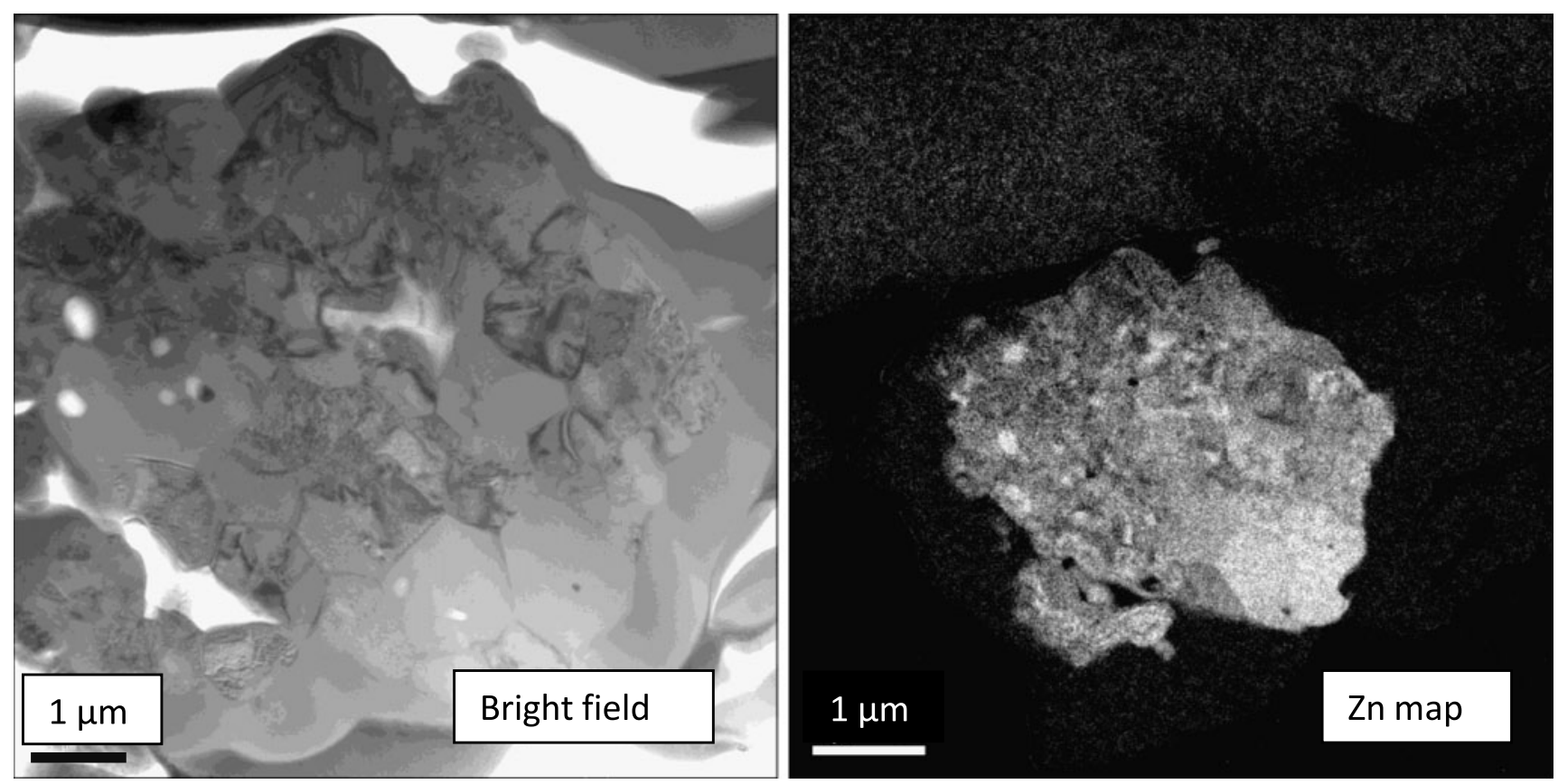

a

b
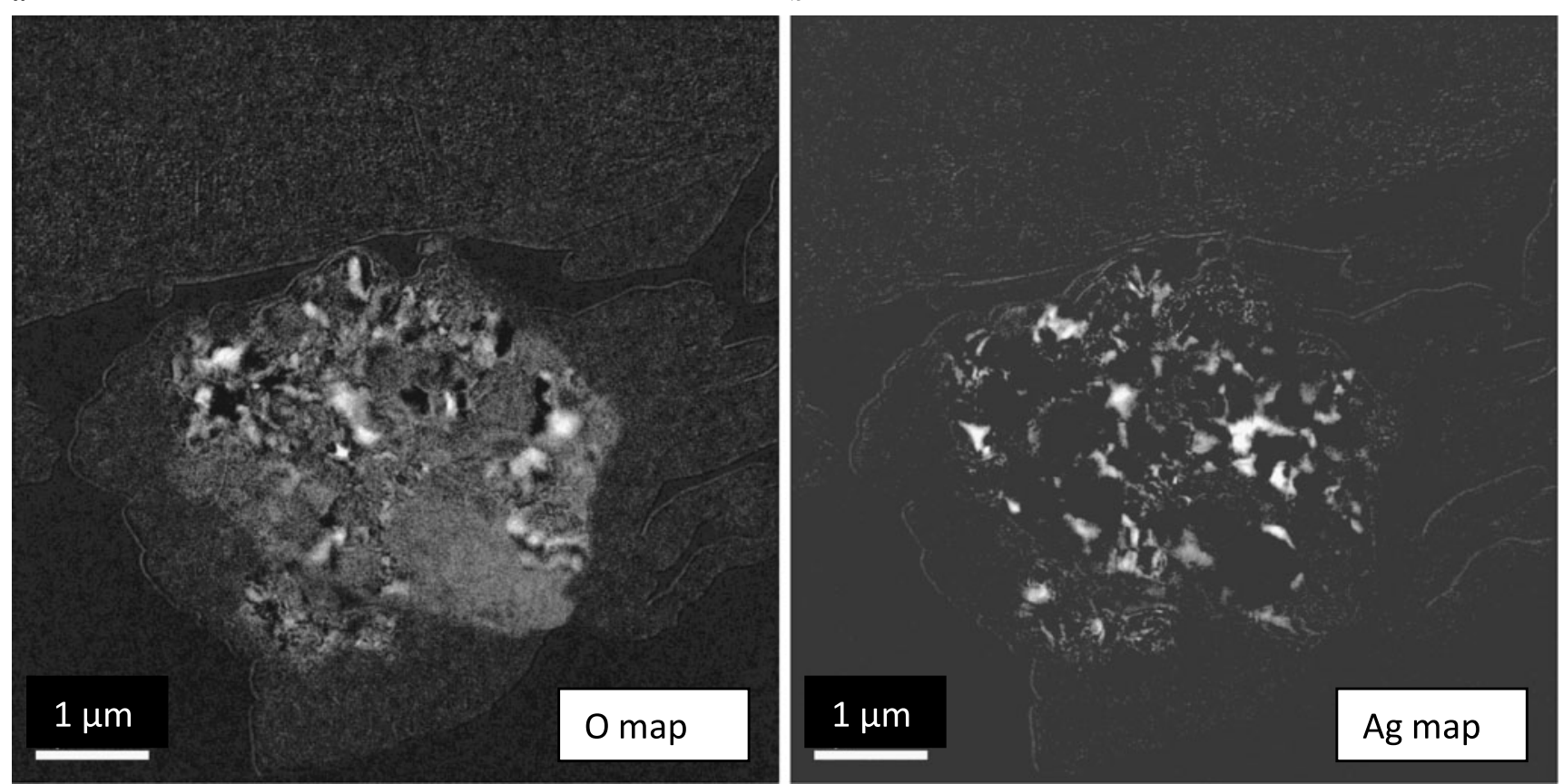

c

d

Fig. 3 TEM images of $1 \times$ plated Ag-doped $\mathrm{ZnO}$ indicating the presence of Ag particles within the $\mathrm{ZnO}$ particle (d). The spatial overlap of $\mathrm{Zn}$ (b) and $\mathrm{O}$ (c) maps indicates that this $\mathrm{Zn}$ particle is fully oxidized

A monolithic $\mathrm{Ag} 1 \times \mathrm{ZnO}$ sample was prepared by the same process used to fabricate the powder samples. After the distillation annealing step, however, the sample was tested intact as opposed to being pulverized and mounted in a capillary tube. Electrodes were formed using conductive epoxy. A representative plot of current density vs. applied field is shown in Fig. 6 for a $\mathrm{ZnO}: \mathrm{Ag}$ monolith of $\sim 0.5 \mathrm{~mm} \times 0.5 \mathrm{~mm} \times 0.5 \mathrm{~mm}$ at $23{ }^{\circ} \mathrm{C}$. The actual current density and applied field values are approximate because the sample was not rectilinear. However, the power law behavior of the sample conduction is well defined. The value of the power law exponent, 2.3, is lower than but similar to exponent values observed in powder samples. 

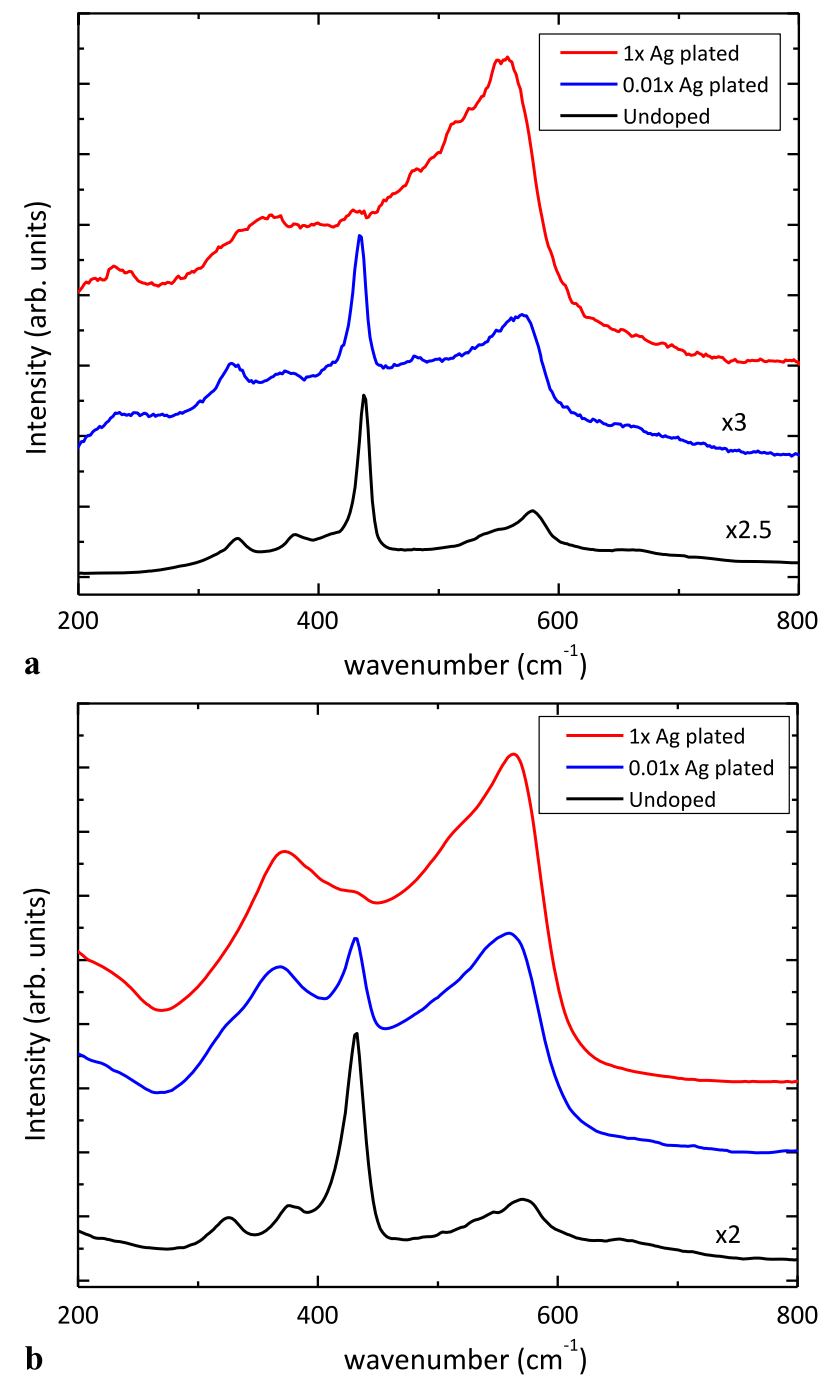

Fig. 4 Raman spectra of $\mathrm{ZnO}$ and $\mathrm{ZnO}: \mathrm{Ag}$ (two $\mathrm{Ag}$ concentrations) excited by $2.33-\mathrm{eV}$ (a) and 1.96-eV (b) laser sources

\section{Discussion}

$\mathrm{ZnO}$ crystallizes in the wurtzite structure (space group $C_{6 v}^{4}$ ) yielding Raman-active phonon modes at the $\Gamma$ point with $\mathrm{A}_{1}, \mathrm{E}_{1}$, and $\mathrm{E}_{2}$ symmetries [16]. $\mathrm{A}_{1}$ and $\mathrm{E}_{1}$ modes are polar and thus split into TO-LO pairs. The $\mathrm{E}_{2}$ doublet is further described by low and high (frequency) branches. Figure 4 shows the largest peak in undoped $\mathrm{ZnO}$ at $437 \mathrm{~cm}^{-1}$, which we can attribute to the non-polar $\mathrm{E}_{2}$ (high) fundamental optical mode in $\mathrm{ZnO}$. This peak has been previously observed to decrease monotonically in $\mathrm{ZnO}: \mathrm{Ag}$ as Ag doping concentration increases from 0 to 5.5 at.\% in 200-nm-thick $\mathrm{ZnO}$ films sputtered on Si substrates (Ag doping by co-sputtering) [17]. However, the decrease was relatively small-a few percent over the full doping range. Furthermore, the enhanced broad peaks we observe at wavenumbers lower and higher than the $\mathrm{E}_{2}$ fundamental optical mode at $437 \mathrm{~cm}^{-1}$ are not observed

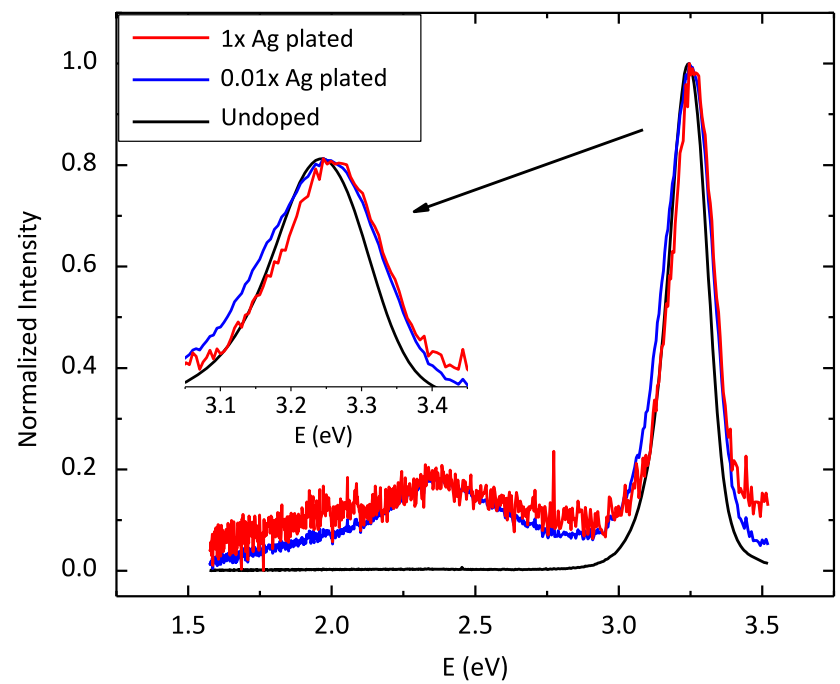

Fig. 5 Room-temperature photoluminescence spectra of $\mathrm{ZnO}$ and $\mathrm{ZnO}: \mathrm{Ag}$ (two Ag concentrations) under 3.53-eV excitation. The inset shows an expanded view of the main band at $\sim 3.25 \mathrm{eV}$ indicating a small energy shift and broadening due to Ag nanoparticle doping

in these co-sputtered thin films. This may indicate the lack of nanostructured $\mathrm{Ag}$ precipitates in the sputtered films.

Also, in $\mathrm{ZnO}: \mathrm{Ag}$ co-sputtered films [17] a local vibrational mode (LVM) at $411 \mathrm{~cm}^{-1}$ increases monotonically in $\mathrm{ZnO}: \mathrm{Ag}$ as $\mathrm{Ag}$ doping concentration increases from 0 to 5.5 at.\%. At $418 \mathrm{~cm}^{-1}$ there is a predicted LVM based on effective mass considerations [18]. Neither peak is directly observable in our spectra, perhaps due to the proximity of other nearby broad, enhanced peaks. For example, in Fig. 4b, a broad enhanced Raman peak spans the range $300-380 \mathrm{~cm}^{-1}$, thus overlapping the reported peak at $\sim 330 \mathrm{~cm}^{-1}$ in $\mathrm{ZnO}$ bulk as well as $\mathrm{ZnO}: \mathrm{Ag}$ nanostructures, which is attributed to a multi-phonon scattering in $\mathrm{ZnO}$ $[16,19]$. However, the absence of the mode at $\sim 330 \mathrm{~cm}^{-1}$ in the $1 \times \mathrm{Ag}$ sample spectra under $2.33-\mathrm{eV}$ excitation and the persistence of the multi-phonon mode show that these modes are in fact distinct.

Figure 4 also shows a broad enhanced Raman peak in the range $525-565 \mathrm{~cm}^{-1}$ for both the $1 \times$ and $0.01 \times \mathrm{Ag}$ concentrations of the Ag-doped $\mathrm{ZnO}$. The enhancement is larger in the case of higher Ag doping, where TEM images showed the presence of nanometer-scale Ag precipitates in the $\mathrm{ZnO}$ matrix. We hypothesize that precipitates form as $\mathrm{Ag}$ is segregated from $\mathrm{Zn}$ when the $\mathrm{Zn}$ oxidizes, and remain in place near grain boundaries and other localized disordered domains.

Enhanced peaks near 568 and $577 \mathrm{~cm}^{-1}$ have been reported by Panda and Jacob [14] and Pachauri et al. [19] in $\mathrm{ZnO}: \mathrm{Ag}$ sword-like nanostructures excited by $514.5-\mathrm{nm}$ laser light. These peaks were attributed to the $\mathrm{A}_{1}(\mathrm{LO})$ and $\mathrm{E}_{1}$ (LO) modes, and it was hypothesized that their enhancement was due to the presence of Ag nanostructures. Activation of $\mathrm{A}_{1}(\mathrm{LO})$ modes through disorder associated with $\mathrm{O}$ 
Fig. 6 Symbols indicate measured current density as a function of applied electric field strength for $\mathrm{ZnO}: \mathrm{Ag}$ particles at $1 \times$ and $0.01 \times$ Ag doping (compressed powder), and $1 \times$ Ag doped monolith. All measurements were performed at $23{ }^{\circ} \mathrm{C}$. Power law fits to the data are shown with solid and dashed lines, together with their functional forms

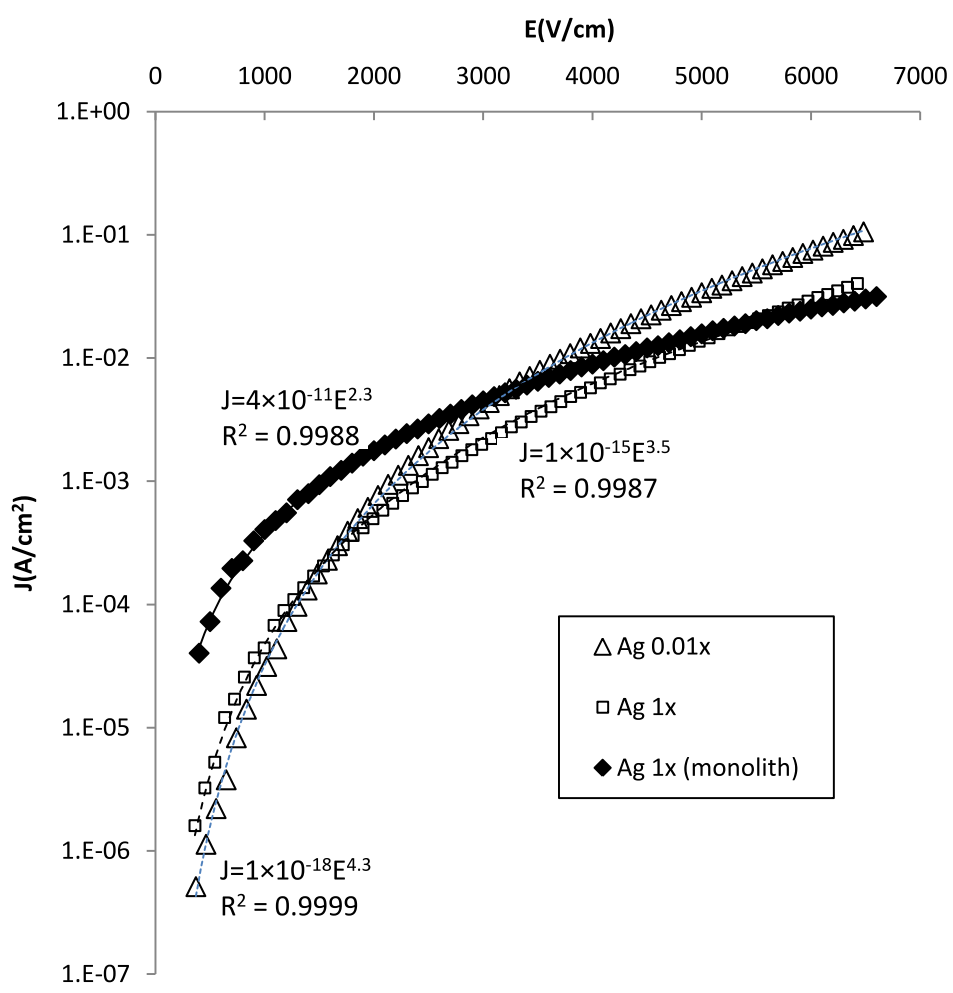

vacancies and/or $\mathrm{Zn}$ interstitials is likely, and may indicate an enhancement of disorder immediately in the vicinity of the Ag nanoparticles. The origin of the $370 \mathrm{~cm}^{-1}$ mode is not presently understood, though the preferred enhancement of the aforementioned LO modes at shorter wavelengths is attributed to band gap resonance effects [20].

It is interesting to note the similarity of our 532-nm $\left(E_{\mathrm{L}}=2.33 \mathrm{eV}\right)$ spectra with those of Panda and Jacob [14] and Pachauri et al. [19] with regard to the absence of an enhanced mode near $370 \mathrm{~cm}^{-1}$. However, the sword-like nanostructures [14] could not be synthesized without Ag, so it was not possible to create control samples without Ag to test the Raman enhancement model. In this work, by contrast, TEM data indicates the presence of Ag nanostructures preferentially in the particles with Ag nanostructured precipitates, where the Raman scattering is enhanced. This correlation represents direct evidence of the role $\mathrm{Ag}$ nanostructures play in creating the enhanced Raman signal, consistent with the observation of enhanced Raman signatures in other Ag nanostructures [21-25]. Moreover, the presence and enhancement of a peak near $530 \mathrm{~cm}^{-1}$ may indicate a similar structural modification to the host $\mathrm{ZnO}$ lattice as observed for Sb-doped films [26].

Though the theoretical origin of surface-enhanced Raman scattering (SERS) has not been definitively established, SERS is currently believed to arise from two principal mechanisms: the formation of a charge-transfer complex between the surface and vibrating species; and an enhanced electromagnetic field produced at the metal surface [27, 28]. Re- garding field enhancement, when the wavelength of the incident light is close to the plasma wavelength of the metal, conduction electrons in the metal surface are excited into an extended surface electronic excited state called a surface plasmon resonance. Vibrational modes active in close proximity to the surface experience an exceptionally large electromagnetic field with out-of-plane displacements most affected. Alternatively, or in conjunction with the plasmon resonance, charge transfer can occur between dopant atoms and the unfilled orbitals of host atoms, with lone-pair electrons or molecular $\pi$ orbitals showing the strongest SERS in organic materials [29].

It is likely that both of the aforementioned enhancement mechanisms are involved in our Ag-doped $\mathrm{ZnO}$ samples and each is observed under different excitation energies. For example, the enhancement of the LVM-like mode near $370 \mathrm{~cm}^{-1}$ at $1.96 \mathrm{eV}$ may indicate a plasmon resonance since plasma coupling is expected to increase at longer wavelengths, while the enhancement of the LO-like mode near 525-565 $\mathrm{cm}^{-1}$ may be due to charge transfer with oxygen surface states. A study focusing on understanding this point, as well as probing into the origin of the $370 \mathrm{~cm}^{-1}$ feature, will be presented in a future work [30].

Under 3.53-eV excitation, the energy of the NBE emission band at $3.25 \mathrm{eV}$ shown in Fig. 5 is observed to have a weak dependence on Ag doping level. A dramatic quenching of the PL signal with doping was also observed, similar to the room-temperature PL intensity changes observed by Wang et al. for $>2.8$ at.\% Ag-doped $\mathrm{ZnO}$ thin films [17]. PL 
quenching has also observed in $\mathrm{Ag}$-coated $\mathrm{ZnO}$ nanorods [31]. In Wang et al. [17], a blue shift of the $~ 3.2-\mathrm{eV}$ PL emission as a function of $\mathrm{Ag}$ doping was observed, and attributed to donor-acceptor pair (DAP) transitions, following the $T=4.2 \mathrm{~K}$ assignment by Meyer et al. for bulk $\mathrm{ZnO}$ [32]. However, as a function of increasing temperature, excitonic transitions (both bound and free) tend to broaden and merge with DAP and free electron and acceptor hole (FA) transitions (for example, see Jeong et al. [33]). Furthermore, the DAP transition in bulk $\mathrm{ZnO}$ is rather weak, and likely not a dominant component of our observed spectrum. On the other hand, free excitons are known to be quite stable in bulk $\mathrm{ZnO}$.

We therefore identify the NBE emission in our $\mathrm{Ag}$ nanoparticle-doped samples with free excitonic recombination. The changes in line width observed associated with doping are presumed due to structural disorder leading to inhomogeneous broadening effects. The slight blue shift may be due to changes in the contribution from bound exciton states $(E>3.24 \mathrm{eV})$ or disorder-induced free exciton binding energy changes. Temperature-dependent studies are needed to further elucidate the mechanisms behind the quenching and energy shifts of the NBE emission in $\mathrm{Ag}$ nanoparticle-doped $\mathrm{ZnO}$. An additional emission band near $2.36 \mathrm{eV}(525 \mathrm{~nm})$ is observed exclusively in the doped $\mathrm{ZnO}$ PL spectra. We attribute this green emission to the recombination of photogenerated holes with singly ionized oxygen vacancies [34]. Interestingly, despite the heavier doping levels in the $1 \times \mathrm{Ag}$ plated samples, the intensity of the $\sim 2.36$ $\mathrm{eV}$ peak relative to that of the $3.25-\mathrm{eV}$ exciton transition is roughly the same as for the $0.01 \times$ plating. This suggests that the $\mathrm{Ag}$ doping does not increase the concentration of oxygen vacancies, and that the latter are intrinsic to the hollow microparticle $\mathrm{ZnO}$ fabrication process.

The current-voltage characteristics of $\mathrm{ZnO}$ varistors are typically described by a power law relationship

$I=k V^{\alpha}$,

where $I$ is current, $V$ is applied voltage, and $\alpha[=\mathrm{d}(\ln I) \mathrm{d}(\ln V)]$ is a nonlinearity constant which varies with voltage. For sintered $\mathrm{ZnO}$ varistors in the breakdown region, $\alpha$ is often in the range $20-50$, and can be as high as 100 [35]. In our unsintered powders, however, the coefficient of nonlinearity is typically much lower, in the range 2-5, as shown in Fig. 6.

Figure 6 shows current-voltage characteristics of monolithic $\mathrm{ZnO}: \mathrm{Ag}$ which are similar to the current-voltage characteristics of particle beds. The current-voltage dependence is well described by a power law. The constant of nonlinearity, 2.3, is lower than but similar to the 4.3 value observed for the similarly doped powder sample. The lower exponent value is consistent with the presence of additional current paths in the monolithic sample, as would be expected in a more highly interconnected monolith of particles. Similar effects with constrained current paths have been observed in polycrystalline silicon thin films [36].

The varistor breakdown voltage $V_{\mathrm{b}}$ is defined at which the device current density $J=1 \mathrm{~mA} / \mathrm{cm}^{2}$ [35]. For our devices, this breakdown voltage corresponds to an electric field of 2000-2500 V/cm (Fig. 6). From bright-field TEM images such as shown in Figs. 1b, 2a, and 3a (together with associated convergent beam electron diffraction patterns, not shown), we observe that a typical $\mathrm{ZnO}$ grain has a diameter of order $100 \mathrm{~nm}$. This implies that at the breakdown field, there is a voltage drop of $0.02-0.025 \mathrm{~V} /$ boundary.

We hypothesize that conduction in our $\mathrm{ZnO}: \mathrm{Ag}$ particle aggregates is controlled by grain boundary resistance in individual particles, similar to the mechanism observed in sintered monolithic $\mathrm{ZnO}: \mathrm{Ag}$ samples [15]. Grain boundary resistance is likely increased in the presence of $\mathrm{Ag}^{+}$ions, segregated to the boundaries because of their larger size relative to $\mathrm{Zn}^{2+}$, since these larger $\mathrm{Ag}^{+}$ions are more readily accommodated in regions of local atomic disorder.

In the case of our unsintered samples, the $0.02-0.025$ voltage drop/boundary is smaller by about a factor of 100 relative to the voltage drop in sintered samples reported in Kuo et al., where average grain diameters are more than 100 times larger [15]. The 100-fold larger surface/volume ratio of the smaller grains may allow for a significantly lower $\mathrm{Ag}$ concentration at each boundary. Furthermore, in the largergrain samples reported in Kuo et al., Ag concentrations are between four and 400 times higher than the highest Ag concentrations that could be present in the unsintered grains reported here. At the relatively dilute Ag concentrations measured for this work (maximum $0.02 \mathrm{~mol} \%$ ), our data suggests that conductivity is not a strong function of $\mathrm{Ag}$ concentration.

Note that nonlinear conduction can be realized in the $\mathrm{ZnO}$ system reported here without sintering, with properties modulated with $\mathrm{Ag}$ doping. Future applications may make use of these properties of $\mathrm{ZnO}$ particles to create nonlinearly conducting films or devices with low-temperature particle deposition processes.

\section{Conclusion}

We reported on synthesis and electrical and optical properties of hollow, spherical Ag-doped $\mathrm{ZnO}$ particles. Starting with metallic $\mathrm{Zn}$ particles, doped hollow $\mathrm{ZnO}$ particles were created with a solution-based plating process followed by a two-step annealing process. Ag doping levels were modified by changing the concentration of $\mathrm{AgNO}_{3}$ in solution in the plating bath. Hollow particles were formed by a thermal oxidation step to create Ag-doped $\mathrm{ZnO}$ shells over metallic $\mathrm{Zn}$ cores, followed by sublimation of the $\mathrm{Zn}$ cores in a second 
thermal step. The hollow microstructure was characterized with scanning electron microscopy after particles were sectioned with a focused ion beam. Focused ion beam milling was also used to prepare electron-transparent structures for characterization with TEM. In the TEM, we employed EDS and elemental mapping to demonstrate the presence of $\mathrm{Ag}$ nanoparticles in more heavily $\mathrm{Ag}$-doped $\mathrm{ZnO}$, and the relative absence of these nanoparticles in lighter-doped $\mathrm{ZnO}$.

Enhanced Raman scattering is seen in both types of particles, but the enhancement is greatest for the $\mathrm{ZnO}$ particles with higher Ag doping, in which Ag nanoparticles were directly observed by TEM. A further enhancement in Raman scattering due to resonance effects was observed for LO phonons at $E_{\mathrm{L}}=2.33 \mathrm{eV}$. Room-temperature PL spectra revealed both a NBE emission due to free exciton transitions which quench and blue shift with $\mathrm{Ag}$ doping, and a mid-gap transition due to the presence of singly ionized oxygen vacancies. Finally, particles were characterized electrically, and we observed nonlinear conduction behavior well described by a power law dependence on electric field. The coefficient of nonlinearity is in the range 2-5 for these samples, which may be appropriate for some electro-optical applications where particle-based thin films and devices are desired.

Acknowledgements This work was performed under the auspices of the U.S. Department of Energy by Lawrence Livermore National Laboratory under Contract DE-AC52-07NA27344.

Open Access This article is distributed under the terms of the Creative Commons Attribution License which permits any use, distribution, and reproduction in any medium, provided the original author(s) and the source are credited.

\section{References}

1. J.C. Johnson, H.Q. Yan, P.D. Yang, R.J. Saykally, J. Phys. Chem. B 107, 8816 (2003)

2. M.H. Huang, S. Mao, H. Feick, H.Q. Yan, Y.Y. Wu, H. Kind, E. Weber, R. Russo, P.D. Yang, Science 292, 1897 (2001)

3. T. Minami, Mater. Res. Soc. Bull. 25, 38 (2000)

4. J. Muller, B. Rech, J. Springer, M. Vanecek, Sol. Energy 77, 917 (2004)

5. H.Y. Liu, V. Avrutin, N. Izyumskaya, U. Ozgur, H. Morkoc, Superlattices Microstruct. 48, 458 (2010)

6. B. Bayraktaroglu, K. Leedy, R. Bedford, Appl. Phys. Lett. 93 (2008)
7. B. Bayraktaroglu, K. Leedy, R. Neidhard, IEEE Electron Device Lett. 30, 946 (2009)

8. D.H. Fan, Appl. Phys. A - Mater. Sci. Process. 96, 655 (2009)

9. Y. Gao, A.D. Li, Z.B. Gu, Q.J. Wang, Y. Zhang, D. Wu, Y.F. Chen, N.B. Ming, S.X. Ouyang, T. Yu, Appl. Phys. Lett. 91 (2007)

10. X.F. Li, K.L. Lu, K.J. Deng, J.F. Tang, R. Su, J. Sun, L.Q. Chen, Mater. Sci. Eng. B - Adv. Funct. Solid-State Mater. 158, 40 (2009)

11. G.Z. Shen, Y. Bando, C.J. Lee, J. Phys. Chem. B 109, 10578 (2005)

12. R. Nakamura, J.G. Lee, D. Tokozakura, H. Mori, H. Nakajima, Mater. Lett. 61, 1060 (2007)

13. J.W. Tringe, H.W. Levie, B.S. El-Dasher, R. Swift, M.A. Wall, Appl. Phys. Lett. 98 (2011)

14. S.K. Panda, C. Jacob, Physica E 792 (2009)

15. S.-T. Kuo, W.-H. Tuan, J. Shieh, S.-F. Wang, J. Eur. Ceram. Soc. 27, 4521 (2007)

16. T.C. Damen, S.P.S. Porto, B. Tell, Phys. Rev. 142, 570 (1966)

17. X.B. Wang, C. Song, K.W. Geng, F. Zeng, F. Pan, J. Phys. D, Appl. Phys. 39, 4992 (2006)

18. A. Kaschner, H. Siegle, G. Kaczmarczyk, M. Strassburg, A. Hoffmann, C. Thomsen, U. Birkle, S. Einfeldt, D. Hommel, Appl. Phys. Lett. 74, 3281 (1999)

19. V. Pachauri, C. Subramaniam, T. Pradeep, Chem. Phys. Lett. 423, 240 (2006)

20. J.M. Calleja, M. Cardona, Phys. Rev. B 16, 3753 (1977)

21. L.A. Dick, A.D. McFarland, C.L. Haynes, R.P. Van Duyne, J. Phys. Chem. B 106, 853 (2002)

22. J.B. Jackson, N.J. Halas, J. Phys. Chem. B 105, 2743 (2001)

23. M. Litorja, C.L. Haynes, A.J. Haes, T.R. Jensen, R.P. Van Duyne, J. Phys. Chem. B 105, 6907 (2001)

24. R.P. Vanduyne, J.C. Hulteen, D.A. Treichel, J. Chem. Phys. 99, 2101 (1993)

25. B.J. Wiley, Y.C. Chen, J.M. McLellan, Y.J. Xiong, Z.Y. Li, D. Ginger, Y.N. Xia, Nano Lett. 7, 1032 (2007)

26. C. Bundesmann, N. Ashkenov, M. Schubert, D. Spemann, T. Butz, E.M. Kaidashev, M. Lorenz, M. Grundmann, Appl. Phys. Lett. 83, 1974 (2003)

27. M. Moskovits, Rev. Mod. Phys. 57, 783 (1985)

28. K.L. Kelly, E. Coronado, L.L. Zhao, G.C. Schatz, J. Phys. Chem. B 107, 668 (2003)

29. F.J. Adrian, J. Chem. Phys. 77, 5302 (1982)

30. M.J. Matthews, J.W. Tringe, to be submitted

31. F. Li, Y.L. Yuan, J.Y. Luo, Q.H. Qin, J.F. Wu, Z. Li, X.T. Huang, Appl. Surf. Sci. 256, 6076 (2010)

32. B.K. Meyer, H. Alves, D.M. Hofmann, W. Kriegseis, D. Forster, F. Bertram, J. Christen, A. Hoffmann, M. Strassburg, M. Dworzak, U. Haboeck, A.V. Rodina, Phys. Status Solidi, B Basic Res. 241, 231 (2004)

33. T.S. Jeong, M.S. Han, C.J. Youn, Y.S. Park, J. Appl. Phys. 96, 175 (2004)

34. K. Vanheusden, W.L. Warren, C.H. Seager, D.R. Tallant, J.A. Voigt, B.E. Gnade, J. Appl. Phys. 79, 7983 (1996)

35. G.D. Mahan, L.M. Levinson, H.R. Philipp, J. Appl. Phys. 50, 2799 (1979)

36. J.W. Tringe, J.D. Plummer, J. Appl. Phys. 87, 7913 (2000) 